Trends in Applied Sciences Research 1 (6): 553-563, 2006

ISSN 1819-3579

(C) Academic Journals Inc., USA

\title{
A Complete Description of Intensity Fields of Thin Isotropic Plates for Flexural Waves in General Field Conditions
}

\author{
Nirmal K. Mandal \\ Centre for Railway Engineering, Central Queensland University, \\ Bruce Highway, Rockhampton, QLD 4702, Australia
}

\begin{abstract}
In engineering practice, structural intensity gives valuable information of sources and sinks of vibration excitations as well as a detailed knowledge of energy propagation through structures. As a result, proper damping treatment can be employed to mitigate noise and vibration harness (NVH) problems. In this study, a complete description of general vibration intensity fields $\left(\mathrm{Wm}^{-1}\right)$ in the frequency domain for isotropic plates is formulated considering flexural waves which is not based on some approximation such as far-field conditions. An 8-point transducer array is required to get an intensity vector in a particular direction taking into account as many as fifteen cross-spectra of field signals. A multichannel FFT analyser is useful for this measurement. However, one transducer frequency response method is also employed to estimate these cross-spectra alternately. It gives the measurements free from phase mismatch errors.
\end{abstract}

Key words: Structural intensity, flexural waves, general-field conditions, frequency response function, isotropic plates

\section{Introduction}

Structural Intensity (SI) or vibration intensity is a valuable tool for localizing and ranking vibration sources and sinks on the structures. It also gives essential information on vibration transmission paths through the structures. As a result, proper damping treatment can be employed to the area of energy transfer on the surfaces to suppress noise and vibration levels of the structures and consequently, less acoustic energy is radiated into the surroundings. Another essential aspect of SI is that it is also useful for the estimation of quantities based on energy flow through joints and junctions such as the transmission loss factors and the reflection coefficients.

Vibration intensity is defined in the solid media, but its measurements can usually be carried out on the surface of the structures. This is because of the fact that in thin structures, the waves, propagated through the structures, could be reasonably assumed that it would be parallel to the surface of the structures (Pavic, 1981). Therefore, it is convenient to use the concept of wave type estimation when addressing the experimental detection of energy flow within the structures. Greater complexity of the mechanical wave field and limited access to the interior of structure bodies, structural vibration implies a higher degree of measurement difficulties as compared to acoustic intensity (Linjama, 1994). This restricts the application of vibration energy flow measurements mainly to relatively simple structures such as pipes, beams and thin plates where propagation of mechanical waves should be considered only parallel to the surface.

SI technique has a unique aspect. It does not depend on boundary conditions of the structures. This enables researchers to investigate the edge effects of vibration power transmission of pipes, plates and beams. But far-field power flow inherently contains some limitations in selecting measurement points. The measurement points should be away from the boundary and inhomogeneities of the plates. The effects of boundaries and inhomogeneities of the plates are called near-field effects. The near field 
effects decay exponentially as function of position and extend to a distance of approximately half the bending wavelength from the boundaries and inhomogeneities of the plates (Noiseux, 1970). At low frequencies, the disturbing near-fields cover a large part of the plate and valid measurement could be made in the center region only. The far-field concept also enables the use of two sensors to determine an intensity vector at a point in the particular direction. The distance between two sensors, called spacing, is selected with regards to bending wavelength, such that the ratio of spacing to bending wavelength is 0.2 for the upper frequency limit and 0.15 for the lower frequency limit (Kay and Swason, 1996). The use of this spacing criterion provides an optimal trade-off between the reduced finite difference errors afforded by small sensor spacing and reduced sensitivity to standing wave related errors (phase errors) afforded by larger sensor spacing.

Most of the works undertaken by SI so far were related to simple structures, typically beams and plates in flexure, using the analysis both in time domain and frequency domain (Noiseux, 1970; Pavic, 1976; Verheij, 1980; Linjama, 1992; Bauman, 1994; Arruda and Campos, 1996). The methods so far presented are contact methods based on finite difference technique. Structural intensity can be computed numerically when predictions of structural behavior in various conditions are needed for complex build-up structures. Vibration intensity, generated by the interaction of dynamic stresses and vibration velocities for beams and plates, can be found by the finite element method (Gavric and Paivc, 1993; Hambric and Taylor, 1994).

Other than contact method and computational technique, some non-contact measurements using near field acoustic holography (NAH) (Williams and Dardy, 1985; Maynard et al., 1985) were proposed and it was successfully applied in plates (Williams et al., 1985) and shells (Romano and Williams, 1993). In this technique a simple microphone or hydrophone was used to detect the acoustic pressure to a plane very close to the vibrating surface.

An optical technique, another approach of non-contact measurements of vibration intensity, is laser vibrometer. The structural intensity can be measured by automated laser vibrometer in plates (Linjama, 1992; Pascal et al., 1993; McDevitt et al., 1993) for bending waves and in beams (Berthelot et al., 1993) for longitudinal waves. In addition to straight beams and flat plates, initial investigations of power flow had been undertaken for curve structure member (Mayer et al., 1988) and structures of arbitrary shape (Pavic, 1987). Recently SI is applied for thin orthotropic plates for estimating vibration energy transfer considering in-plane waves (Mandal et al., 2000;2006) and flexural waves for far-field conditions (Mandal et al., 2002, 2005). Mandal and Biswas (2005) presented a review to emphasis the usefulness of this method for noise and vibration control in industries.

It has been seen, using related literature search, that vibration energy transfer has been mainly explored using two-transducer method (Noiseux, 1970; Pavic, 1976; Verheij, 1980; Linjama and Lahti, 1992; Bauman, 1994). It is very easy to use and gives good results with reasonable accuracy (Linjama and Lahti, 1992). So far, no complete description of general intensity fields for isotropic plates in the frequency domain is available. In the case of low frequency analysis when bending wavelength is higher, two-transducer method in the frequency domain (Linjama and Lahti, 1992) is not suitable for practical measurements. Less area on the plates is available for measurement. Therefore, a general structural intensity in the frequency domain is necessary for plates. This is the purpose of this article. Thin isotropic plates are usually used in industry especially in automotive, aircraft and ship structures. Consequently this method can be successfully used in industrial applications for noise and vibration control.

\section{Theory}

\section{Classical Isotropic Plate Theory}

This study considers a thin homogeneous isotropic plate with small deflections compared to the uniform thickness of the plate. The idea of thin plate results when the thickness of the plate, $h$, is small 

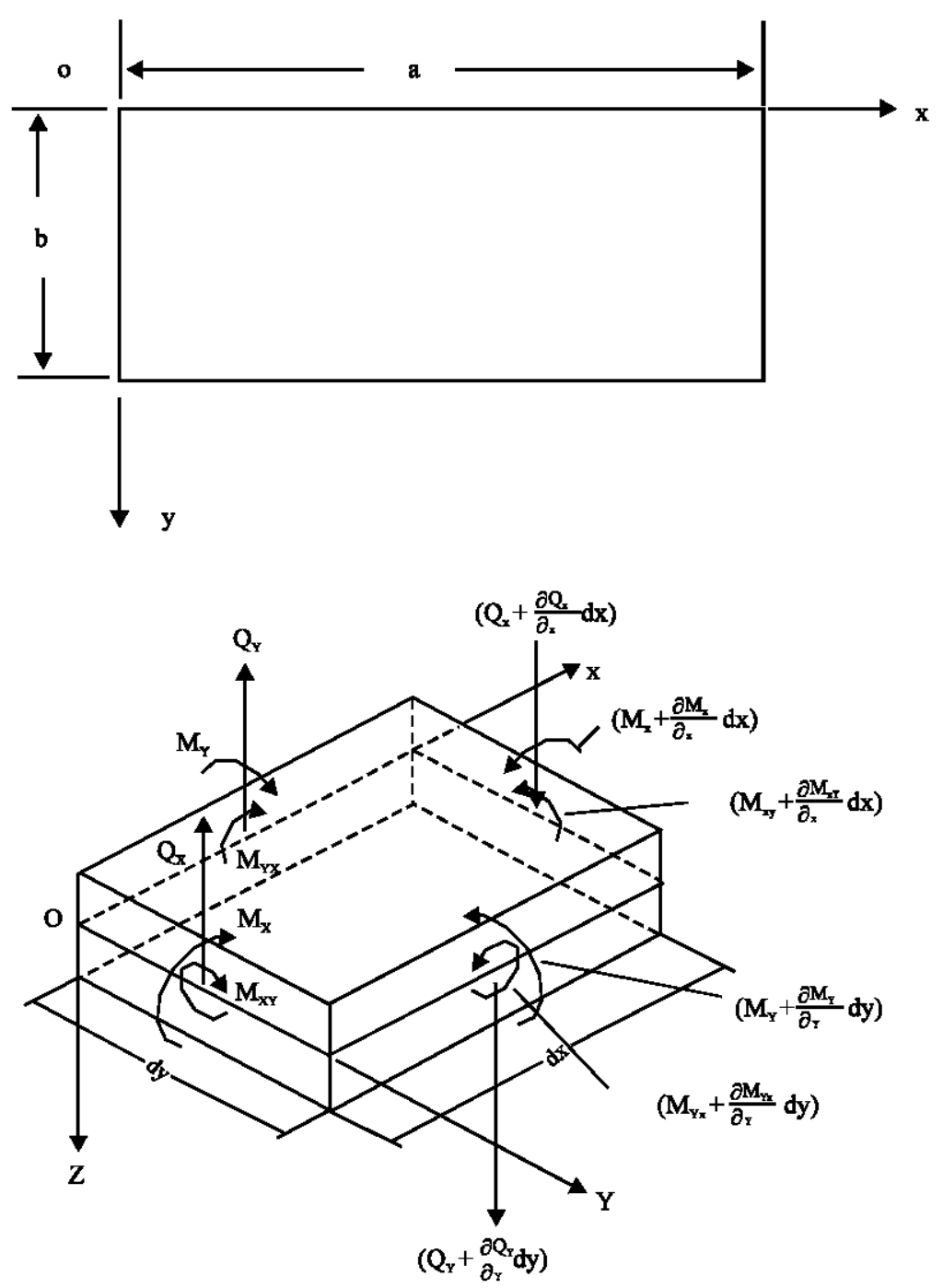

Fig. 1: Schematic diagram of plate with its small element: typical plate with co-ordinate systems (above), internal shear force and moments on small element (below)

enough compared to other dimensions. In thin plate flexural wave equation, the influence of rotary inertia and shear deformation are neglected. This approximation is valid when $h<<\lambda$, the flexural wave length (Cremer and Heckl, 1988). It is considered in this analysis.

A typical coordinate plane xoy coincides with the middle plane of the plate denoting downward direction of z-axis positive as shown in the Fig. 1. The thin plate assumption implies a plane stress state, given by the following stress-strain relations expressed in the coordinate system parallel to the principal material directions with no body forces.

$$
\left\{\begin{array}{l}
\sigma_{\mathrm{z}} \\
\sigma_{\mathrm{y}} \\
\tau_{\mathrm{xy}}
\end{array}\right\}=\left[\begin{array}{ccc}
\mathrm{U}_{11} & \mathrm{U}_{12} & \mathrm{U}_{16} \\
\mathrm{U}_{12} & \mathrm{U}_{22} & \mathrm{U}_{26} \\
\mathrm{U}_{16} & \mathrm{U}_{26} & \mathrm{U}_{66}
\end{array}\right]\left\{\begin{array}{l}
\varepsilon_{\mathrm{z}} \\
\varepsilon_{\mathrm{y}} \\
\gamma_{\mathrm{xy}}
\end{array}\right\}
$$


where $\sigma_{x}, \sigma_{y}, \tau_{x y}$ are in-plane normal and shear stress components, $\varepsilon_{z}, \varepsilon_{y}, \lambda_{x y}$ are in-plane normal and shear strain components. $U_{i j}$ is the stiffness matrix which can be defined in terms of engineering constants:

$$
\mathrm{U}_{11}=\mathrm{U}_{22}=\frac{\mathrm{E}}{1-v^{2}}, \quad \mathrm{U}_{12}=\frac{\mathrm{E} v}{1-v^{2}}, \mathrm{U}_{66}=\mathrm{G}, \quad \mathrm{U}_{16}=\mathrm{U}_{26}=0
$$

where, E is the Young modulus, G, the shear modulus and v, the Poisson's ratio.

The bending moments $M_{x}, M_{y}$ and the twisting moments $M_{x y}$ along with the vertical shearing forces, $Q_{x}$ and $Q_{y}$, the magnitudes of all moments and the forces are per unit length shown in Fig. 1, can be expressed as (Cremer and Heck1, 1988):

$$
\begin{aligned}
& M_{x}=-D\left(\frac{\partial^{2} w}{\partial x^{2}}+v \frac{\partial^{2} w}{\partial y^{2}}\right), \quad M_{y}=-D\left(\frac{\partial^{2} w}{\partial y^{2}}+v \frac{\partial^{2} w}{\partial x^{2}}\right), \quad M_{x y}=-D_{x y} \frac{\partial^{2} w}{\partial x \partial y} \\
& Q_{x}=-D \frac{\partial}{\partial x}\left(\frac{\partial^{2} w}{\partial x^{2}}+\frac{\partial^{2} w}{\partial y^{2}}\right), \quad Q_{y}=-D \frac{\partial}{\partial y}\left(\frac{\partial^{2} w}{\partial x^{2}}+\frac{\partial^{2} w}{\partial y^{2}}\right)
\end{aligned}
$$

Where $\mathrm{D}$ is called the flexural rigidity and the quantity $\mathrm{D}_{\mathrm{xy}}$ is called torsional rigidity of the plate such as,

$$
\mathrm{D}=\frac{\mathrm{Eh}^{3}}{12\left(1-v^{2}\right)}, \quad \text { and } \quad \mathrm{D}_{\mathrm{xy}}=\frac{G h^{3}}{12}
$$

\section{Complex Power Flow}

The power in the frequency domain (spectral density, W/Hz) is defined as a conjugate product of the Fourier transforms $\bar{v}(f)$ and $\bar{F}$ (f) of the time domain signals $v(t)$ and $F(t)$ of transverse velocity and input force as:

$$
P(f)=\bar{v}^{*}(f) \bar{F}(f)
$$

Where the asterisk denotes complex conjugate and $\mathrm{f}$ is frequency. This complex power, $\mathrm{P}(\mathrm{f})$, has two components such as active power and reactive power. The active power is generally the quantity of interest since it is associated with the energy flow. The order of conjugating of the signals only affects the sign of reactive power. The complex power $\mathrm{P}(\mathrm{f})$ can be estimated by the one-sided crossspectral density function $\mathrm{G}_{\mathrm{VF}}$ (f) (Bandat and Piersol, 1986) of the signals. This one-sided crossspectral density function can be expressed as (Linjama and Lahti, 1992):

$$
\mathrm{G}_{\mathrm{vF}}(\mathrm{f})=\left\langle\bar{v}^{*}(\mathrm{f}) \overline{\mathrm{F}}(\mathrm{f})\right\rangle \text {, where }<>\text { denotes the ensemble average. }
$$

The real part of the complex power corresponds to the time average net power, called active power, $\mathrm{I}$, is given by

$$
\mathrm{I}=\operatorname{Re}\left\{\mathrm{G}_{\mathrm{vF}}(\mathrm{f})\right.
$$

The imaginary part of the complex power, called energy density, is defined as the standing wave power per unit width or it can be described alternately as that portion of the energy which resides in the stationary waves and is, essentially, stored within the medium. 
In the flexural wave field, the contribution of complex power results from shear force (Q) and moments: one bending moment $(\mathrm{M})$ and other one twisting moment $\left(\mathrm{M}_{\mathrm{xy}}\right)$ together with transverse velocity (v) and angular velocity $(\dot{\theta})$. In the following section, complex power flow formulation is carried out for shear force followed by moment contributions. Differentiating all the moment and shear force equations with respect to time and performing Fourier transform of all, it is possible to get the moment and shear force equations in terms of transverse velocity (v) of the plate.

$$
\begin{aligned}
& \bar{M}_{x}=-\frac{D}{j \omega}\left(\frac{\partial^{2} \bar{v}}{\partial x^{2}}+v \frac{\partial^{2} \bar{v}}{\partial y^{2}}\right), \quad \bar{M}_{x y}=-\frac{2 D_{x y}}{j \omega x} \frac{\partial^{2} \bar{v}}{\partial x \partial y} \text { and } \\
& \bar{Q}_{x}=-\frac{1}{j \omega} D\left(\frac{\partial^{3} \bar{v}}{\partial x^{3}}+\frac{\partial^{3} \bar{v}}{\partial x \partial y^{2}}\right)
\end{aligned}
$$

$\mathrm{P}_{\mathrm{xS}}$ and $\mathrm{P}_{\mathrm{xM}}$, the components of complex power from shear force and moments respectively in the $\mathrm{x}$-direction of the plate, are given by:

$$
P_{x S}(f)=G_{v Q_{x}} \text { (f) and } P_{x M}=G_{\dot{\theta}_{x} M_{x}}(f)+G_{\dot{\theta}_{y} M_{x y}} \text { (f) }
$$

Where $G_{v z}$ (f) is the cross-spectrum of transverse velocity and shear force along a plane perpendicular to $x$-axis and $G_{\dot{\theta}_{x} M_{x}}$ (f) and $G_{\dot{\theta}_{y} M_{x y}}$ (f) are the cross-spectra of the angular velocities $(\theta)$ with bending moment and twisting moment. The total real part of complex power in the $\mathrm{x}$ direction can be obtained either by summing of the real part of $P_{x S}(f)$ and $P_{x M}(f)$ or by taking the real part of the sum of $\mathrm{P}_{\mathrm{zS}}(\mathrm{f})$ and $\mathrm{P}_{\mathrm{zM}}(\mathrm{f})$. The former option is illustrated below,

$$
\operatorname{Re}\left\{\mathrm{P}_{\mathrm{z}}(\mathrm{f})\right\}=\operatorname{Re}\left\{\mathrm{G}_{\mathrm{vQ}}\right\}+\operatorname{Re}\left\{\mathrm{G}_{\dot{\theta}_{\mathrm{x}} \mathrm{M}_{\mathrm{x}}}(\mathrm{f})+\mathrm{G}_{\dot{\theta}_{y} \mathrm{M}_{x y}}(\mathrm{f})\right\}
$$

Here $\operatorname{Re}\left\{\mathrm{P}_{\mathrm{x}}(\mathrm{f})\right\}$ denotes the real part or active part of complex power, $\mathrm{P}_{\mathrm{x}}(\mathrm{f})$ in the $\mathrm{x}$-direction of the plate.

\section{Complex Power from Shear Force}

The field quantities of shear force component power at a particular point are the transverse velocity and shear force at that point. The spatial derivatives of these field quantities can be obtained by using the finite difference approximations of velocity signals using eight-point transducer array (Fig. 2) (Pavic, 1976).

In terms of Fourier transformed transverse velocity, the spatial derivatives of shear force and transverse velocity can be obtained as:

$$
\begin{aligned}
& \overline{\mathrm{Q}}_{\mathrm{x}} \approx-\frac{\mathrm{D}}{\mathrm{j \omega \textrm {d } ^ { 3 }}}\left(\bar{v}_{1}+\bar{v}_{2}-5 \bar{v}_{3}+\bar{v}_{4}+5 \bar{v}_{6}-\bar{v}_{7}-\bar{v}_{8}\right) \\
& \bar{v} \approx \frac{1}{2}\left(\bar{v}_{3}+\bar{v}_{6}\right)
\end{aligned}
$$

Complex power from the shear force component in the $\mathrm{x}$-direction of the plate, $\mathrm{P}_{\mathrm{xS}}(\mathrm{f})$, can be obtained as:

$$
\mathrm{P}_{\mathrm{xS}}(\mathrm{f})=\frac{\mathrm{D}}{2 j \omega \mathrm{d}^{3}}<\left(\bar{v}_{3}+\bar{v}_{6}\right)^{*}\left(\bar{v}_{1}+\bar{v}_{2}-5 \bar{v}_{3}+\bar{v}_{4}+5 \bar{v}_{6}-\bar{v}_{7}-\bar{v}_{8}\right)>
$$




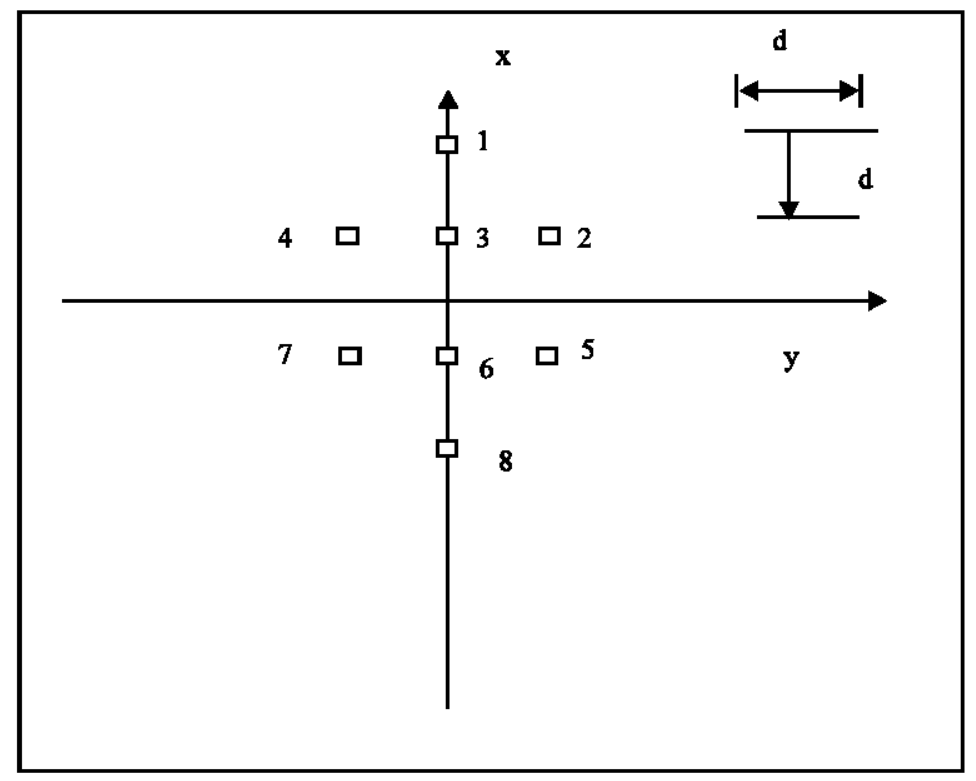

Fig. 2: 8-point measurement array (spacing not in scale)

where $d$ is the transducer spacing (Fig. 2). Negative sign of shear force is cancelled by the negative sign imposed in the velocity term on power flow formulation so as to make a positive power flow in positive direction (Pavic, 1976).

Noting that $\left\langle\bar{v}_{\mathrm{i}}{ }^{*} \quad \bar{v}_{\mathrm{j}}>=\mathrm{G}_{\mathrm{ij}}\right.$ and $\mathrm{G}_{\mathrm{ji}}{ }^{*} \quad=\mathrm{G}_{\mathrm{ij}}$ and taking the averages of all the terms in the ensemble average notation separately, the final form of shear force component of complex power can be obtained as follows,

$$
\begin{aligned}
P_{x S}(f)= & \frac{D}{2 j \omega d^{3}}\left\{5\left(G_{66}-G_{33}\right)+10 j \operatorname{Im}\left(G_{36}\right)+G_{31}+G_{32}+G_{34}-G_{35}-G_{37}-G_{38}+\right. \\
& \left.G_{61}+G_{62}+G_{64}-G_{65}-G_{67}-G_{68}\right\}
\end{aligned}
$$

All the cross-spectral terms rather than auto-spectral terms of velocity signals in the above equation are complex. Active power of the shear force component alone in the $\mathrm{x}$-direction of the plate, $\mathrm{I}_{\mathrm{xS}}$, can thus be obtained by taking the real part of the above complex power equation.

$$
\begin{aligned}
I_{x S}=\operatorname{Re}\left\{P_{x S}(f)\right\}= & \frac{D}{2 \omega d^{3}}\left[\operatorname { I m } \left\{10 G_{36}+G_{31}+G_{32}+G_{34}-G_{35}-G_{37}-G_{38}+\right.\right. \\
& \left.\left.G_{61}+G_{62}+G_{64}-G_{65}-G_{67}-G_{68}\right\}\right] .
\end{aligned}
$$

\section{Complex Power from Moment Components}

The spatial derivatives of bending and twisting moment and its angular velocities $\left(\dot{\theta}_{\mathrm{z}}\right.$ and $\left.\dot{\theta}_{\mathrm{y}}\right)$ can be obtained in terms of Fourier transformed transverse velocity of the plates using an 8-point transducer array (Fig. 2) as: 


$$
\begin{aligned}
& \bar{M}_{\mathrm{x}} \approx-\frac{\mathrm{D}}{\mathrm{j \omega}}\left\{\frac{1}{2 \mathrm{~d}^{2}}\left(\bar{v}_{1}-\bar{v}_{3}-\bar{v}_{6}+\bar{v}_{8}\right)+\frac{v}{2 \mathrm{~d}^{2}}\left(\bar{v}_{2}-2 \bar{v}_{3}+\bar{v}_{4}-2 \bar{v}_{6}+\bar{v}_{7}\right)\right\} \text { and } \\
& \overline{\mathrm{M}}_{\mathrm{xy}} \approx \frac{-\mathrm{D}(1-v)}{\mathrm{j} \omega}\left\{\frac{1}{2 \mathrm{~d}^{2}}\left(\bar{v}_{2}-\bar{v}_{4}-\bar{v}_{5}+\bar{v}_{7}\right)\right\} \\
& \dot{\theta}_{\mathrm{x}} \approx \frac{1}{\mathrm{~d}}\left(\bar{v}_{3}-\bar{v}_{6}\right) \text { and } \dot{\theta}_{\mathrm{y}} \approx \frac{1}{4 \mathrm{~d}}\left(\bar{v}_{2}-\bar{v}_{4}+\bar{v}_{5}-\bar{v}_{7}\right)
\end{aligned}
$$

Similarly as in the case of shear force component, the real part of complex power of moment component in $\mathrm{x}$-direction of the plate, $\mathrm{I}_{\mathrm{xM}}$ may be obtained as:

$$
\begin{aligned}
I_{x M}= & \operatorname{Re}\left\{P_{x M}(f)\right\}=\frac{D}{2 \omega d^{3}}\left[\operatorname { I m } \left\{2 G_{36}-G_{31}-G_{38}+G_{61}+G_{68}+v\left(4 G_{36}-\right.\right.\right. \\
& \left.G_{32}-G_{34}-G_{35}-G_{37}+G_{62}+G_{64}+G_{65}+G_{67}\right)+\frac{(1-v)}{2}\left(G_{25}-\right. \\
& \left.\left.G_{27}-G_{45}+G_{47}\right)\right] .
\end{aligned}
$$

\section{Total Power}

Total active power in the $\mathrm{x}$-direction of the plate can be achieved by adding the Eq. (10) and (11) as:

$$
\begin{aligned}
& \mathrm{I}_{\mathrm{x}}=\frac{\mathrm{D}}{2 \omega \mathrm{d}^{3}}\left[\operatorname { I m } \left\{(12+4 v) \mathrm{G}_{36}+(1-v) \mathrm{G}_{32}+(1-v) \mathrm{G}_{34}-(1+v) \mathrm{G}_{35}-\right.\right. \\
& (1+v) \mathrm{G}_{37}-2 \mathrm{G}_{38}+2 \mathrm{G}_{61}+(1+v) \mathrm{G}_{62}+(1+v) \mathrm{G}_{64}-(1-v) \mathrm{G}_{65}-(1-v) \mathrm{G}_{67}+ \\
& \left.\left.\frac{1-v}{2}\left(\mathrm{G}_{25}-\mathrm{G}_{27}-\mathrm{G}_{45}+\mathrm{G}_{47}\right)\right\}\right]
\end{aligned}
$$

This general energy transmission model in the $\mathrm{x}$-direction of the plate (Eq. 12) cannot be considered as an exact because of the finite difference approximation. To estimate the general structural intensity equation of bending waves in isotropic plates requires simultaneous acquisition of fifteen cross-spectra of field velocity signals $\left(\mathrm{G}_{\mathrm{ij}}\right)$ using a multi-channel FFT analyzer. It is also possible to re-model the equation using cross-spectra of acceleration signals. Similarly, the y-component of general energy transmission could be obtained. In this case, it is necessary to interchange the suffix of I ' $\mathrm{x}$ ' by $y$ in the eq. (12) and to rotate the measuring 8-point cell (Fig. 2) by 90 degree so as to make it parallel to $\mathrm{y}$-axis.

Velocity was taken as a key term in the mathematical modeling of power flow. Since accelerometers are widely used in vibration measurements, it is therefore customary to use acceleration signals instead of velocity signals in the formulation of energy transfer.

In the frequency domain, the relation between velocity and acceleration is $\bar{v}=\frac{\bar{a}}{j \omega}$. This leads to $\mathrm{G}_{\mathrm{w}}=\frac{\mathrm{G}_{\mathrm{aa}}}{\omega^{2}}$ for power spectral densities of velocity and acceleration where $\bar{v}$ and $\overline{\mathrm{a}}$ are the signals of velocity and acceleration in the frequency domain respectively. The following cross-spectra, $\mathrm{G}_{\mathrm{ij}}$ refer to the signals of acceleration rather than velocity signals. Using the cross-spectral field signals of acceleration, the $\mathrm{x}$-component of energy transmission would be: 


$$
\begin{aligned}
& \mathrm{I}_{\mathrm{x}}=\frac{\mathrm{D}}{2 \omega^{3} \mathrm{~d}^{3}}\left[\operatorname { I m } \left\{(12+4 v) \mathrm{G}_{36}+(1-v) \mathrm{G}_{32}+(1-v) \mathrm{G}_{34}-(1+v) \mathrm{G}_{35}-\right.\right. \\
& (1+v) \mathrm{G}_{37}-2 \mathrm{G}_{38}+2 \mathrm{G}_{61}+(1+v) \mathrm{G}_{62}+(1+v) \mathrm{G}_{64}-(1-v) \mathrm{G}_{65}-(1-v) \mathrm{G}_{67}+ \\
& \left.\left.\frac{1-v}{2}\left(\mathrm{G}_{25}-\mathrm{G}_{27}-\mathrm{G}_{45}+\mathrm{G}_{47}\right)\right\}\right]
\end{aligned}
$$

where, all fifteen $\mathrm{G}_{\mathrm{ij}}$ are cross-spectra of acceleration signals. The $\mathrm{y}$-component of intensity vector can be obtained by only changing the subscript $x$ to $y$ and re-positioning the measurement array parallel to $\mathrm{y}$-direction.

\section{Complex Power by Frequency Response Function (FRF) Method}

It is necessary to get simultaneous acquisition of all cross-spectra of acceleration field signals of Eq. (13) for an intensity vector at a point on the structure to a particular direction. Consequently, an eight channel FFT analyser or more is required. If one-transducer FRF method be used, it is still possible to obtain all cross-spectra by conventional two-channel FFT analyser. The first cross-spectrum of the intensity equation in Eq. (13) is $\mathrm{G}_{36}$. Two accelerometers, one on point 3 and another one on point 6 (Fig. 2) are necessary. An estimate of this cross-spectrum, $G_{36}$ can be obtained with this FRF method (Bandat and Piersol, 1986) using one accelerometer as follows

$$
\tilde{\mathrm{G}}_{36}=\mathrm{H}_{\mathrm{F} 3}^{*} \mathrm{H}_{\mathrm{F} 6} \mathrm{G}_{\mathrm{FF}}
$$

where $\tilde{G}_{36}$ is the estimate of true $\mathrm{G}_{36}, \mathrm{H}_{\mathrm{F} 3}$ and $\mathrm{H}_{\mathrm{F} 6}$ are the frequency response functions of a force (reference) signal to accelerations at points 3 and $6 . \mathrm{G}_{\mathrm{FF}}$ is the auto spectrum of force signal. This method has no phase error problem.

In some practical situations, it is not possible to measure exciting force. In such a situation, it is still possible to estimate the cross-spectra of the Eq. (13), using acceleration signals at any arbitrary point as reference. Using this idea, the same estimate of cross-spectrum in Eq. (14) can be obtained as:

$$
\tilde{\mathrm{G}}_{36}=\mathrm{H}^{*}{ }_{\mathrm{a} 3} \mathrm{H}_{\mathrm{a} 6} \mathrm{G}_{\mathrm{aa}}
$$

Here FRF is between reference signal of acceleration at any position and acceleration to the positions 3 and 6 . If phase error is not a problem in the measurement, it is possible to make a reference acceleration signal at first measuring point 3 , the first suffix point of the cross-spectrum, $G_{36}$, the Eq. (15) takes a simpler form as:

$$
\tilde{\mathrm{G}}_{36}=\mathrm{H}_{36} \mathrm{G}_{33}
$$

Similarly, other cross-spectra in Eq. (13) can be evaluated using one-transducer FRF technique positioning one accelerometer sequentially to all required positions. As the number of cross-spectrum increases, time required for this method is also increased significantly. Estimating all cross-spectral terms using a frequency response method, the structural intensity Eq. (13) can be written incorporating auto-spectrum of reference force signal, $\mathrm{G}_{\mathrm{FF}}$, as: 


$$
\begin{aligned}
& \mathrm{I}_{\mathrm{z}}=\frac{\mathrm{D}}{2 \omega^{3} \mathrm{~d}^{3}} \operatorname{Im}\left[\left\{(12+4 v) \mathrm{H}_{\mathrm{F} 3}^{*} \mathrm{H}_{\mathrm{F} 6}+(1-v) \mathrm{H}_{\mathrm{F} 3}^{*} \mathrm{H}_{\mathrm{F} 2}+(1-v) \mathrm{H}_{\mathrm{F} 3}^{*} \mathrm{H}_{\mathrm{F} 4}-\right.\right. \\
& (1+v) \mathrm{H}_{\mathrm{F} 3}^{*} \mathrm{H}_{\mathrm{F} 5}-(1+v) \mathrm{H}_{\mathrm{F} 3}^{*} \mathrm{H}_{\mathrm{F} 7}-2 \mathrm{H}_{\mathrm{F} 3}^{*} \mathrm{H}_{\mathrm{F} 8}+2 \mathrm{H}_{\mathrm{F} 6}^{*} \mathrm{H}_{\mathrm{F} 1}+(1+v) \mathrm{H}_{\mathrm{F} 6}^{*} \mathrm{H}_{\mathrm{F} 2}+ \\
& (1+v) \mathrm{H}_{\mathrm{F} 6}^{*} \mathrm{H}_{\mathrm{F} 4}-(1-v) \mathrm{H}_{\mathrm{F} 6}^{*} \mathrm{H}_{\mathrm{F} 5}-(1-v) \mathrm{H}_{\mathrm{F} 6}^{*} \mathrm{H}_{\mathrm{F} 7}+\frac{1-v}{2}\left(\mathrm{H}_{\mathrm{F} 2}^{*} \mathrm{H}_{\mathrm{F} 5}-\right. \\
& \left.\left.\mathrm{H}_{\mathrm{F} 2}^{*} \mathrm{H}_{\mathrm{F} 7}-\mathrm{H}_{\mathrm{F} 4}^{*} \mathrm{H}_{\mathrm{F} 5}+\mathrm{H}_{\mathrm{F} 4}^{*} \mathrm{H}_{\mathrm{F} 7}\right) \mathrm{G}_{\mathrm{FF}}\right]
\end{aligned}
$$

Considering frequency response function of reference acceleration and using auto-spectrum of acceleration, the above Eq. (17) can also be written as:

$$
\begin{aligned}
& \mathrm{I}_{\mathrm{z}}=\frac{\mathrm{D}}{2 \omega^{3} \mathrm{~d}^{3}} \operatorname{Im}\left[\left\{(12+4 v) \mathrm{H}_{\mathrm{a} 3}^{*} \mathrm{H}_{\mathrm{a} 6}+(1-v) \mathrm{H}_{\mathrm{a} 3}^{*} \mathrm{H}_{\mathrm{a} 2}+(1-v) \mathrm{H}_{\mathrm{a} 3}^{*} \mathrm{H}_{\mathrm{a} 4}-\right.\right. \\
& (1+v) \mathrm{H}_{\mathrm{a} 3}^{*} \mathrm{H}_{\mathrm{a} 5}-(1+v) \mathrm{H}_{\mathrm{a} 3}^{*} \mathrm{H}_{\mathrm{a} 7}-2 \mathrm{H}^{*}{ }_{\mathrm{a} 3} \mathrm{H}_{\mathrm{a} 8}+2 \mathrm{H}_{\mathrm{a} 6}^{*} \mathrm{H}_{\mathrm{a} 1}+(1+v) \mathrm{H}^{*}{ }_{\mathrm{a} 6} \mathrm{H}_{\mathrm{a} 2}+ \\
& (1+v) \mathrm{H}_{\mathrm{a} 6}^{*} \mathrm{H}_{\mathrm{a} 4}-(1-v) \mathrm{H}_{\mathrm{a} 6}^{*} \mathrm{H}_{\mathrm{a} 5}-(1-v) \mathrm{H}_{\mathrm{a} 6}^{*} \mathrm{H}_{\mathrm{a} 7}+\frac{1-v}{2}\left(\mathrm{H}_{\mathrm{a} 2}^{*} \mathrm{H}_{\mathrm{a} 5}-\right. \\
& \left.\left.\left.\mathrm{H}^{*}{ }_{\mathrm{a} 2} \mathrm{H}_{\mathrm{a} 7}-\mathrm{H}^{*}{ }_{\mathrm{a} 4} \mathrm{H}_{\mathrm{a} 5}+\mathrm{H}^{*}{ }_{\mathrm{a} 4} \mathrm{H}_{\mathrm{a} 7}\right)\right\} \mathrm{G}_{\mathrm{a} a}\right]
\end{aligned}
$$

Using the idea of Eq. (16), making the acceleration reference signal to the first suffix point of cross-spectrum, the Eq. (18) can be further written as:

$$
\begin{aligned}
& \mathrm{I}_{\mathrm{x}}=\frac{\mathrm{D}}{2 \omega^{3} \mathrm{~d}^{3}} \operatorname{Im}\left[\left\{(12+4 v) \mathrm{H}_{36}+(1-v) \mathrm{H}_{32}+(1-v) \mathrm{H}_{34}-(1+v) \mathrm{H}_{35}-\right.\right. \\
& \left.(1+v) \mathrm{H}_{37}-2 \mathrm{H}_{38}\right\} \mathrm{G}_{33}+\left\{2 \mathrm{H}_{61}+(1+v) \mathrm{H}_{62}+(1+v) \mathrm{H}_{64}-(1-v) \mathrm{H}_{65}-\right. \\
& \left.\left.(1-v) \mathrm{H}_{67}\right\} \mathrm{G}_{66}+\frac{1-v}{2}\left\{\left(\mathrm{H}_{25}-\mathrm{H}_{27}\right) \mathrm{G}_{22}-\left(\mathrm{H}_{45}-\mathrm{H}_{47}\right) \mathrm{G}_{44}\right\}\right]
\end{aligned}
$$

\section{Discussion}

Mathematical modeling of SI for the isotropic plates was performed in frequency domain considering 8-point transducer array method and one transducer frequency response method. Finite difference approximation and Fourier transform are used in these formulations. There are several reasons for selection of this approach as compared to a direct time domain implementation. The completed integrals and derivatives in time domain power can be replaced by spectral approach in frequency domain and it is carried out internally by FFT analyzer.

If an eight-channel FFT analyser is available, simultaneous acquisition of all fifteen cross-spectra (Eq. 13) and their ensemble averages can be obtained readily to obtain energy transfer in one direction. A total of sixteen accelerometers are necessary to get a complete intensity vector. Alternately, a one-transducer frequency response technique may be employed to get all cross-spectra (Eq. 17) sequentially using a familiar two-channel FFT analyser. This method is free from phase errors.

It is well known that the shorter is the spacing, $\mathrm{d}$, of the sensors, the less is the finite difference error. On the other hand, the shorter is the spacing, the greater is the phase mismatch error. Therefore, it is necessary to make a trade-off for selecting a suitable spacing of transducer keeping all errors to a minimum level. The criteria for selecting spacing are available in literature (Linjama, 1994; Kay and Swanson, 1996; Linjama and Lahti, 1992). The maximum value of $d / \lambda$ should be $1 / 5(=0.2)$ (Kay and Swanson, 1996; Linjama and Lahti, 1992) and higher than this, finite difference error starts to appear. 
The phase mismatch error, on the other hand, comes due to mismatch of phase. The phase error, generally, results due to small spacing relative to flexural wave length and a reverberant vibration field. It can be quite large if the coherence values are not close to unity. In eight-point and two-point transducer methods, both finite difference and phase mismatch errors occur readily. A proper strategy is necessary to make the error magnitudes to an acceptable level. These errors are not a problem in onetransducer method, where vibration field should be stationary. The selection of transducer (accelerometer) in 8-point method is very critical such that the mass of accelerometers should be much less so as not to disturb vibration fields due to its mass, stiffness and cabling. The problem of mass loading is very minimal in one transducer frequency response method.

Minimization of error depends on the selection of spacing, end-damping, number of average taken in data acquisition and good values of coherence functions between input and output quantities. Random errors, on the other hand, occur by virtue of its nature and it would not be a problem if a large amount of averages is taken during data acquisition (Linjama, 1994).

The eight-point transducer method, by contract to two-transducer method, gives more flexible measurement environment by providing its measurements very close to vibration sources and edges of the structures. As it does not depend on sources and boundary conditions, eventually it can measure energy transmission in the presence of near field effects. As a result, a more complete vibration propagation field can be figured out.

\section{Conclusions}

Using the classical isotropic plate theory for flexural waves, a general model of vibration energy transfer is formulated. The study considers finite difference approximation to model spatial derivatives of force and moment quantities. The study is carried in the frequency domain considering fast Fourier transform. Simultaneous acquisitions of fifteen cross-spectra of accelerometer signals of the plate are needed for a particular direction which can be obtained by multi-channel FFT analyser. Different forms of estimation of cross-spectrum are put forward by one transducer frequency response method so as to make the measurement free from phase errors.

\section{References}

Arruda, J.R.F. and J.P. Campos, 1996. Experimental determination of flexural power flow in beams using a modified prony method. J. Sound Vib., 197: 309-328.

Bandat, J.S. and A.G. Piersol, 1986. Random Data: Analysis and Measurement Procedures. New York: Jhon Wiley, 2nd Edn.

Bauman, P.D., 1994. Analytical and experimental evaluation of various techniques for the case of flexural waves in one-dimensional structures. J. Sound Vib., 174: 677-694.

Berthelot, Y.H., M. Yang and J. Jarzynski, 1993. Recent progress on laser doppler measurement in structural acoustics. Proceeding of the 4th International Congress on Intensity Technique, Senlis, France, pp: 199-206.

Cremer, L. and M. Heckl, 1988. Structure-Borne Sound: Structural Vibration and Sound Radiation at Audio Frequencies. Springer-Verlag, Berlin.

Gavric, L. and G. Pavic, 1993. A finite element method for computation of structural intensity by the normal mode approach. J. Sound Vib., 164: 29-43.

Hambric, S.A. and P.D. Taylor, 1994. Comparison of experimental and finite element structure-borne flexural power measurements for a straight beams. J. Sound Vib., 170: 595- 605.

Kay, K.Q. and D.C. Swanson, 1996. Error in bending wave power measurements. Noise Cont. Eng. J., 44: 185-192. 
Linjama, J., 1992. Structural intensity measurements using two laser vibrometers. Inter-Noise 92: 541-544.

Linjama, J. and T. Lahti, 1992. Estimation of bending wave intensity in beams using the frequency response technique. J. Sound Vib., 153: 21-36.

Linjama, J., 1994. Propagation of mechanical vibration in structure, experimental development of the vibration intensity method. VTT Publication 170, Technical Research Centre of Finland.

Mandal, N.K., R.A. Rahman and M.S. Leong, 2000. Measurement of quasi-longitudinal wave power in thin single-layer orthotropic plates. Intl. J. Acou. Vib., 5: 106-108.

Mandal, N.K., Rahman, R. Abd. and M.S. Leong, 2002. Prediction of Structure borne sound in orthotropic plates for far field conditions. J. Vib. Cont., 8: 3-12.

Mandal, N.K., Rahman, R. Abd. and M. Salman Leong, 2005. Experimental investigation of vibration power flow in thin technical orthotropic plates by the method of vibration intensity. J. Sound Vib., 285: 669-695.

Mandal, N.K. and S. Biswas, 2005. Vibration power flow: A critical review. The Shock and Vibration Digest, 37: 3-11.

Mandal, N.K., 2006. Experimental studies of quasi-longitudinal waves power flow in corrugated plates. J. Sound Vib., (In Press).

Mayer, B., J.M. Silvestre and D. Thomasson, 1988. Detection of vibration sources in cylinders by structural intensity method. Inter-Noise, 88 : 575-578.

Maynard, J.D., Williams, E.G. and Y. Lee, 1985. Near field acoustic holography: I. Theory of generalised holography and development of NAH. J. Acoust. Soc. Am., 78: 1395-1413.

McDevitt, T.E., Koopmann, G.H. and C.B. Burroughs, 1993. Two-channel laser vibrometer techniques for vibration intensity measurements. Part 1: Flexural intensity. J. Vib. Acoust., 115 : 436-440.

Noiseux, D.U., 1970. Measurement of power flow in uniform beams and plates. J. Acou. Soc. Am., 47: $238-247$.

Pascal, J.C., T. Loyau and X. Carniel, 1993. Complete determination of structural intensity in plates using laser vibrometers. J. Sound Vib., 161: 527-531.

Pavic, G., 1976. Measurement of structure borne wave intensity. Part I: Formulation of the methods. J. Sound Vib., 49: 221-230.

Pavic, G., 1981. Determination of sound power-flow in structures: principles and problems of realization. Proceeding of International Congress on Recent Developments in Acoustic Intensity Measurements, CETIM, Senlis France, pp: 209-215.

Pavic, G., 1987. Structural surface intensity: An alternative approach in vibration analysis and diagnosis. J. Sound Vib., 115: 405-422.

Romano, A.J. and E.G. Williams, 1993. On the use of acoustic holography for the determination of intensity of structures. Proceeding of the 4th International Congress on Intensity Technique, Senlis, France pp: 13-34.

Verheij, J.W., 1980. Cross-spectral density methods for measuring structure borne power flow on beams and pipes. J. Sound Vib., 70: 133-138.

Williams, E.G. and H.G. Dardy, 1985. Near filed acoustic holography using an underwater-automated scanner. J. Acoust. Soc. Am., 78: 789-798.

Williams, E.G., H.G. Dardy and R.G. Fink, 1985. A technique for measurement of structure-borne intensity in plates. J. Acoust. Soc. Am., 78: 2061-2968. 